\title{
A Non-Linear Analysis of Gibson's Paradox
}

\author{
Guglielmo Maria Caporale ${ }^{1}$, Marinko Skare ${ }^{2}$
}

\author{
${ }^{1}$ Brunel University London \\ Kingston Lane, Uxbridge Middlesex UB8 3PH, UK \\ E-mail.Guglielmo-Maria.Caporale@brunel.ac.uk \\ ${ }^{2}$ Juraj Dobrila University of Pula \\ Preradoviceva 1/1 52100 Pula, Croatia \\ E-mail.mskare@unipu.hr
}

cross $^{\text {ref }}$ http://dx.doi.org/10.5755/j01.ee.29.4.20403

\begin{abstract}
Keynes (1930) considered the Gibson's relation as the "most completely established empirical fact". In contrast to the previous literature, this paper adopts a multivariate, nonlinear framework to analyse Gibson's paradox in the Netherlands over the period 1800-2012. Specifically, SSA (Singular Spectrum Analysis) and MSSA (Multichannel Singular Spectrum Analysis) techniques are used. It is shown that changes in monetary policy regimes or volatility in the price of gold by themselves cannot account for the behaviour of government bond yields and prices over the last 200 years. However, the inclusion of changes in the real rate of return on capital, M1, primary credit rate, expected inflation, and money purchasing power enables a nonlinear model to account for a sizeable percentage of the total variance of Dutch bond yields. This is a novel study of the Gibson's paradox using a non-linear approach unravelling the multidimensional nature of the paradox. The results should assist policy makers in setting monetary policy and help to better understand the behaviour of financial institutions on the markets. Central banks, should however evaluate the implication of this study in setting inflation targeting goals. Results of this study are also expected to stimulate further research on the bank credit policies by managing interest rates.
\end{abstract}

Keywords: Gibson's Paradox; Singular Spectrum Analysis; Interest Rates; Causality; The Netherlands.

\section{Introduction}

The long-run relationship between bond yields and prices first noticed by Gibson (1923), has become known in the literature as Gibson's paradox. Numerous studies have been carried out and have failed to account for it: Friedman \& Schwartz (1976) in fact defined it as an "empirical phenomenon without a theoretical explanation". The original study by Gibson (1923) examined the long-run correlation between the cost of living and bond yields (consols) in Britain. Fisher (1930) focused on expected inflation to explain the difference between nominal and real interest rates and resolve the paradox. By contrast, Keynes (1930) interpreted it in terms of the so-called Keynes' effect: in his opinion, long-term nominal interest rates move together with the natural rate of interest (with a lag), which accounts for the co-movement between interest rates and prices. The Harrod-Keynes effect, (Clayton, Gilbert, \& Sedgwick, 1971) link inflation to the real as opposed to the nominal rate. Other studies emphasise the role of the gold standard, Barsky \& Summers (1988), Cheng, Kesselring, \& Brown, (2013), Faria \& McAdam (2012) or of changes in monetary policy as in (Cogley, Sargent, \& Surico, 2011), Mills (2008). Unconventional monetary policy could also have significant impact on the Gibson's law (Belke, 2016) and technology impact on the banking industry (Waldemar \& Maciej, 2016). Shiller \& Siegel (1977) investigate the relationship between long-term nominal and real interest rate fluctuations. Modern studies explore the dynamics between stock returns and inflation (Rizwan, Vveinhardt,
Streimikiene \& Fayyaz, 2017) and financial leverage and stock returns (Mirza, Rahat \& Reddy, 2016). Economic shocks also have considerable impact on the sovereign bond market (Dajcman, 2015). More recent study shows that a part of the link can be explained by a flatter New Keynesian Phillips curve (Casares \& Vazques, 2018).

A major point of difference in explaining the Gibson's paradox is the nature of the paradox itself. Looking at the paradox on a single factor basis and not as a multifactor (better say multidimensional) phenomena resulted in a large number of previous study leaving the source of the paradox undiscovered. Gibson's paradox even outdated in some case in today modern financial markets still bear important knowledge to the policy makers in setting up monetary policy based on inflation targeting and managing market interest rates. The present study analyses Gibson's paradox in the case of the Netherlands. In contrast to earlier contributions, such as Fields (1984) and Fase (1972), it uses a long span of data for the period 1800-2012 and adopts a very general nonlinear framework based on spectral analysis as well as considering 73 potential explanatory variables. Singular Spectrum Analysis and related models have been used in this study in order to address possible nonstationarity and structural breaks issues in this context. Past research on Netherlands have concentrated on shorter time periods and used mainly standard linear econometric techniques. Consequently, we have an incomplete idea of the true nature of the paradox observed by Gibson (1923). Here we use a non-linear approach in the form of SSA (Singular Spectrum Analysis) and MSSA (Multichannel 
Singular Spectrum Analysis). This study attempts to identify the true nature of the paradox, explain why the paradox is not as strong as before in order to drive attention of policy makers on possible negative outcomes in using unconventional monetary policy over the long run. In addition, this research will also assist financial markets in re-examining their standard interest rate management policies.

The purpose of this research is to examine main determinants behind the Gibson's law in the Netherlands. The findings of this paper are expected to assist policy makers in setting up consistent inflation targeting policies and monitor the mechanism behind interest rate dynamics on the financial markets.

The rest of the paper is structured as follows. Section 2 presents the data and outlines the methodology. Section 3 discusses the empirical findings. Section 4 provides some concluding remarks.

\section{Data and Methodology \\ Data Sources and Description}

This study uses a data set including 73 variables that could potentially be relevant to explaining Gibson's paradox in the Netherlands over the period 1800-2012. The series have been obtained from following sources: Zanden \& Riel (2000), Zanden \& Lindblad (1989), Smits, Horlings, \& Van Zanden (2000), Hart, Jonker, \& van Zanden (2010), van Bochove \& Huitker (1987), Netherland (2010), (Netherland, 2012), CBS - Historical series - Publications (2013), International Institute of Social History (2013), Homer \& Sylla (2011), Jacobs \& Smits (2001), Barro \& Ursua, (2008), Officer \& Williamson (2013), Bos (2008), Groote, Albers, \& De Jong (1996), Homepage Statistics - De Nederlandsche Bank (2013), van den End (2011).

In some cases observations were missing for the periods 1800-1813, 1913-1917, 1939-1946. In such cases the SSA Reconstruction/Prediction filter (Kspectra program 3.4) has been used to fill the gaps, following Harvey (1990), Hamilton (1994), and Priestley (1981). Samples and variable descriptions are listed in Table 1 . In the end only 15 of the 73 variables were included in the empirical model, on the basis of data availability, theoretical considerations and pre-processing analysis (PCA screening).

Table 1

Model Variables Description

\begin{tabular}{|c|c|c|}
\hline Time Series ID & Sample & Variable description \\
\hline LR & $1800-2012$ & Long-term interest rate yield on Consols (government bonds) in \% \\
\hline CPI & $1800-2012$ & Consumer prices index $1995=100$ \\
\hline EXPSTIR & $1800-2012$ & $\begin{array}{l}\text { Expected Short-term interest rate on capital market in } \% \text { measured using univariate unobserved } \\
\text { component filter }\end{array}$ \\
\hline DEBT & $1800-2012$ & Total debt/GDP ratio \\
\hline EXP3 & $1800-2012$ & Expected inflation calculated as in (Barsky, 1987) \\
\hline NIR6 & $1800-2012$ & $\begin{array}{l}\text { Natural interest rate calculated with multivariate Hodrick-Prescott filter } \lambda=6.25 \text { as in (Gonzalez, } \\
\text { Melo, Rojas and Rojas, 2010) }\end{array}$ \\
\hline RORK2 & $1800-2012$ & Real rate of return on capital calculated as in (Caselli \& Feyrer, 2007) \\
\hline PPG & $1800-2012$ & Purchasing power (guilder) \\
\hline TURNOVER & $1800-2012$ & Change in business inventories $\%$ of GDP \\
\hline M1 & $1800-2012$ & Money supply (million guilder, current prices) \\
\hline EXPP & $1800-2012$ & $\begin{array}{l}\text { Expected rate of profitability measured using multivariate unobserved component filter with } \\
\text { three explanatory variable (wage index, productivity, stocks) }\end{array}$ \\
\hline UN & $1800-2012$ & Unemployment rate in percent \\
\hline GOLDSIL & $1800-2012$ & Gold/Silver Price Ratio (ounces of silver per ounce of gold) \\
\hline VOL & $1800-2012$ & Gold price volatility measured using $\operatorname{GORCH}(2,3)$ model - conditional standard deviation \\
\hline DR & $1800-2012$ & De Nederlansche Bank (DNB) bank discount rate (primary credit rate) in percent \\
\hline
\end{tabular}

Source: Study data sources and author's calculations

\section{Descriptive Analysis}

Co-movement between long-term interest rates (LR yields on Consols) and consumer prices (CPI - consumer price index 1995=100) as described in Gibson (1923) is clearly present in the Netherlands. However, a break occurred after WWII. An even stronger correlation can be seen between short-term rates and prices.

Further evidence is provided by Table 2, which reports the correlation coefficients for different sub-samples. It would suggest that Gibson's paradox only existed in the 19th century. However, such a conclusion, based on static sample correlations, would be misleading.

It is clear from the data that changes in monetary policy regimes and the adoption of the gold standard by themselves cannot explain the observed Gibson's paradox. A bimetallic silver/gold standard regime was present in the Netherlands in the period 1815-1848, whilst the classical gold standard regime was in place in 1875-1913, was suspended in 19141925, readopted in 1926-1936, and then abandoned. Gibson's paradox was present in the Netherlands both under the classical gold regime and when this regime was 
abandoned or suspended. Another policy regime change (i.e., Netherlands joining EMU) had a large impact on the price-interest link: from 1999 bond yields declined rapidly while prices remained stable.

Table 2

Coefficients of Correlation between LR and CPI, $\log$ CPI in The Netherlands 1800-2012

\begin{tabular}{lccc}
\hline Periods & LR and CPI & LR and $\log C P I$ & Gibson paradox existence \\
\hline $1800-1850$ & $0.73^{*}$ & $0.74^{*}$ & YES \\
$1850-1900$ & $0.79^{*}$ & $0.80^{*}$ & YES \\
$1900-1950$ & $0.11^{*}$ & $0.23^{*}$ & YES \\
$1950-2012$ & $-0.12^{*}$ & $0.09^{*}$ & Until 2009 and after NO \\
\hline
\end{tabular}

*At the $5 \%$ confidence level Source: Author's calculation

Gibson's paradox is clearly observable in the Netherlands from the beginning of the 19th century till the 1970s. Then it started becoming less important, completely disappearing (with the correlation between LR and CPI becoming negative) after 2008. The correlation coefficients for different sub-samples (see Table 1) indicate that it was present in various sub-periods, and therefore the significant correlation coefficient is not just due to the big size of the sample.

\section{Statistical Framework}

Spectral techniques are used in this study to examine the correlation between LR and CPI. A moving window correlation coefficient is calculated to establish whether or not there is a Gibson's paradox in the Dutch economy, as a (significant) positive coefficient would indicate. Spectral analysis allows to decompose the LR series into different frequency bands. The estimated spectrum shows periodicity and oscillations in long-term bond yields. Three different spectral measures are used here, namely Squared Coherency, Gain and the Phase spectrum. (1981)

The Coherency spectrum is calculated as in Priestley

$\left|\hat{w}_{i j}(\omega)\right|=\frac{\left|\hat{h}_{i j}(\omega)\right|}{\left\{\hat{h}_{i i}(\omega) \hat{h}_{j j}(\omega)\right\}^{1 / 2}}=\left\{\frac{\hat{c}_{i j}(\omega)+\hat{q}_{i j}^{2}(\omega)}{\hat{h}_{i i}(\omega) \hat{h}_{j j}(\omega)}\right\}^{1 / 2}$

where $\widehat{w}_{i j}$ is coherency at frequency $(\omega)$, $\hat{c}_{i j}(\omega)$ represents the co-spectrum and $\hat{q}_{i j}^{2}(\omega)$ is the quadrature spectrum. Coherency has the same interpretation as $\mathrm{R}^{2}$ in the time domain and measures the proportion of the variance of LR at a given frequency explained by the variance of LCPI (the logarithm of the consumer price index). A value around 0.50 is thought to be relatively small, whilst values above 0.75 are considered significant.

The Gain (spectrum) statistic has the same interpretation as the regression coefficient in the linear regression, see Engle (1976).

$G_{x y}()=\left|f_{x y}()\right| / f_{x}()$

$G_{x y}(\theta)$ being the gain, $f_{x y}(\theta)$ the cross-amplitude spectrum and $f_{x}(\theta)$ the input spectrum.
High gain values (0.8-1.0) associated with high coherence values $(>0.75)$ would indicate that fluctuations in prices were transmitted to long-term bond yields.

The Phase spectrum $\phi_{x y}(\omega)$ shows the lead/lag relationship between LR and LCPI and can be expressed in the form as in Warner (1998).

$\phi_{x, y}(\omega)=\arctan \left[\frac{\operatorname{Im} g_{x, y}(\omega)}{\operatorname{Re} g_{x, y}(\omega)}\right]$

At high frequencies $(\omega)$, when the squared coherency is largest, the phase spectrum has positive values, suggesting that price changes lead to LR changes.

Nonlinearity tests (not reported here), specifically the BDS test - Broock, Scheinkman, Dechert, \& LeBaron (1996) and one of its variants, Kocenda (2001) detect nonlinear behaviour in the LR, CPI and LCPI series. For this reason, SSA (Singular Spectrum Analysis) and MSSA (Multichannel Singular Spectrum Analysis) techniques are used in this study. SSA detects trends, oscillatory patterns and noise in the series. The single channel SSA involves two main steps: decomposition and reconstruction. Decomposition is obtained by embedding the original time series (LR, LCPI) into lagged vector sequences of the form (trajectory matrix), Golyandina \& Zhigljavsky (2013).

$$
X=\left[X_{1}: \ldots: X_{K}\right]^{\prime}=\left(\begin{array}{cccc}
f_{1} & f_{2} & \cdots & f_{L} \\
f_{2} & f_{3} & \cdots & f_{L+1} \\
\vdots & \vdots & \ddots & \vdots \\
f_{K} & f_{K+1} & \cdots & f_{n}
\end{array}\right) .
$$

A singular value decomposition of the trajectory matrix (4) has the form $\mathrm{X}=\mathrm{X}_{1}+\ldots+\mathrm{X}_{d}$ with $X_{i}=\sqrt{\lambda_{i}} U_{i} V_{i}^{T}$. The diagonal averaging method is applied to reconstruct the original LR time series as the sum of the identified principal components. The Eigentriple grouping takes the form $X=X_{I_{1}}+\ldots+X_{I_{m}}$ with the input series LR decomposed as

$x_{n}=\sum_{k=1}^{m} \tilde{x}_{n}^{(k)}$

with $\mathrm{n}=1,2, \ldots, \mathrm{N}$, Golyandina \& Zhigljavsky (2013).

Singular spectrum analysis is used to decompose the series and to isolate the trend, periodic and oscillatory components in the bond yields series. Since the relationship between LR and LCPI is the focus of the analysis, SSA has to be extended to the multichannel singular spectrum. The trajectory matrix in this case takes the following form Golyandina \& Zhigljavsky (2013):

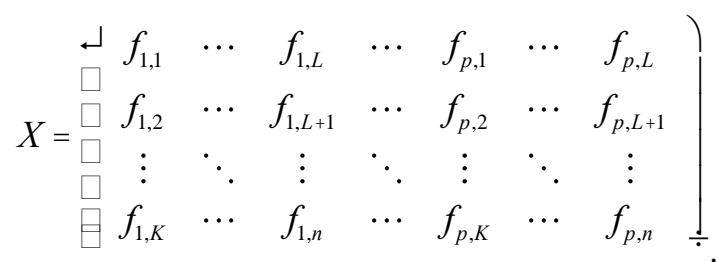

with the Toeplitz "grand" block matrix, Ghil et al. (2002) 


$$
\tilde{T}_{x}=\left(\begin{array}{cccccc}
T_{1,1} & T_{1,2} & \cdot & \cdot & \cdot & T_{1, L} \\
T_{2,1} & T_{2,2} & \cdot & & & \\
\cdot & \cdot & \cdot & \cdot & & \cdot \\
\cdot & \cdot & \cdot & \cdot & T_{l, l^{\prime}} & \cdot \\
\cdot & \cdot & \cdot & \cdot & & \cdot \\
\cdot & & & \cdot & \cdot & T_{L-1, L} \\
T_{L, 1} & \cdot & \cdot & \cdot & T_{L, L-1} & T_{L, L}
\end{array}\right) .
$$

The following covariance matrix is used to identify and extract the spatial temporal structure (the principal patterns in time as well as in space) of the underlying stochastic process:

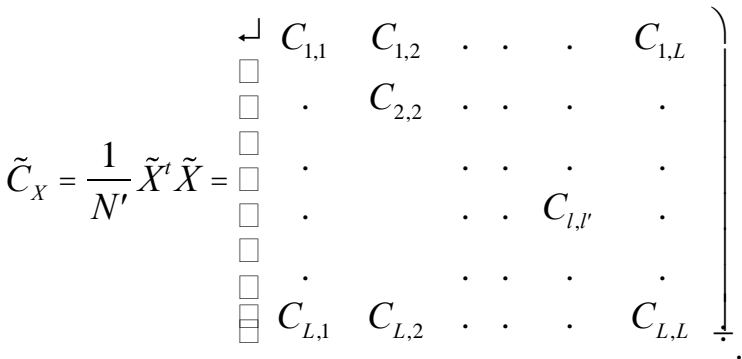

To test for the statistical significance of the identified oscillatory channels (the extracted spectral components) a Monte Carlo test (MC-SSA) of Allen and Smith (1996) against the red noise null hypothesis following $\mathrm{AR}(1)$ is performed, for more details see Ghil \& Yiou (1996), Ghil and Taricco (1997). It takes the following form:

$$
X_{t}=a_{1}\left[X(t-1)-X_{0}\right]+\sigma \xi(t)+X_{0^{\prime}}
$$

where $X_{0}$ is the mean of the process, $a_{l}$ the constant and $\sigma$ the variance under the assumption of a Gaussian white noise process $\xi$. To check the robustness of the MSSA results (i.e., the statistical significance of the identified oscillations), a Granger causality test based on singular spectrum analysis is carried out following Hassani et al. (2011):

$$
F_{X \mid Y}^{(h, d)}=\frac{\Delta_{X_{K+H_{x}} \mid Y_{K+H_{y}}}}{\Delta_{X_{K+H_{x}}}}
$$

with $\Delta_{X_{K+H_{x}}} \equiv \mathrm{L}\left(X_{K+H_{x}}-\hat{X}_{K+H_{x}}\right)$ representing the mean square forecast error from the univariate SSA, and $\Delta_{X_{K+H_{x}} \mid Y_{K+H_{y}}} \equiv \mathcal{L}\left(X_{K+H_{x}}-\tilde{X}_{K+H_{x}}\right)$ including $X_{T}$ and $Y_{T+1}$ (the lagged differenced series) being the mean square forecast error from MSSA. If $F_{X \mid Y}^{(h, d)}<1, Y_{T+1}$ Granger causes $X_{T}$, whilst if $F_{X \mid Y}^{(h, d)}>1$ there is no association between $X_{T}$ and $Y_{T+1}$. Bivariate Granger causality (forecasting feedback) exists if both $F_{X \mid Y}^{(h, d)}<1$ and
$F_{Y \mid X}^{(h, d)}<1$

The forecasting efficiency of the MSSA model is assessed by the means of the Mariano and Diebold (1995) test specified as in Hassani et al. (2011) :

$$
S=\bar{D} \sqrt{\frac{n+1-2 h+h(h-1) / n}{\widehat{n \operatorname{var}}(\bar{D})}}
$$

with $(\bar{D})$ being the sample mean of the vector $D_{t}$ and $\widehat{\operatorname{var}}(\bar{D})$ the autocovariance of $D_{t}$.

Several empirical issues have to be addressed in this context. For instance, Groth and Ghil (2011) highlight the difficulty of identifying the oscillation patterns when the corresponding eigenvalues are similar in size. The VARIMAX rotation for the MSSA algorithm is used here to address this issue.

The number of observations $(n)$ for all series $n=213$ satisfies the condition set by Granger \& Hatanaka (1964) for the minimum $n$. Since spectral analysis (Toeplitz structure) assumes stationarity of the series, all of them were centered, normalised (with the mean removed and divided by the standard deviation) and differenced to achieve stationarity. Following Granger \& Hatanaka (1964), Elsner \& Tsonis (1996), Golyandina, Nekrutkin, \& Zhigljavsky (2010), an optimal window size should be chosen applying the general rule $\mathrm{m}=\mathrm{N}_{\mathrm{t}} / 2, \mathrm{~N}_{\mathrm{t}} / 3, \mathrm{~N}_{\mathrm{t}} / 4$. The MSSA specification was introduced by Hassani \& Mahmoudvand (2013) and the SSA-based causality test by Hassani, Heravi, \& Zhigljavsky (2012). The optimal window size has been chosen applying the rule of thumb for SSA as in Hassani, Zhigljavsky, Patterson, \& Soofi (2011) and Hassani et al. (2012). For the Multivariate Singular Spectrum Analysis the window size has been selected following Hassani \& Mahmoudvand (2013).

\section{Empirical Results}

\section{Spectral Analysis}

The results from spectral analysis can be summarised as follows:

1. The coherence between LR and LCPI is high implying that movements in one series have a strong and long lasting effect on the other, with LCPI affecting LR in particular.

2. The gain coefficient is higher for LCPI than for LR, indicating that movements in the former have a larger impact on the latter than vice versa.

3. The phase angle is close to zero and $2 \pi$, therefore LR and LCPI are simultaneously affecting each other both in the short and long run.

Overall, the spectral analysis provides evidence of strong correlation between LR and LCPI (i.e., of a Gibson's paradox in the Netherlands), but gives no information on causality linkages. A Multichannel Singular Spectrum Causality (MSSA) test, outlined in the next section, is carried out to shed light on causation. 
Multichannel Singular Spectrum Analysis

On the basis of the Cochrane-Orcutt AR(1) procedure and logit regression results (not reported here) we select 15 variables (statistically most significant) from the pool of total 73 variables examined in this study. Selected variables are CPI, DEBT, VOL, EXPSTIR, GOLDSIL, TURNOVER, RORK2, UN, M1, EXPP, DR, NIR6, EXP3, PPG. VOL stands for gold price volatility and is a proxy for the gold standard regime shift, with no effect on the price-interest rate link. DR is the DNB bank discount rate (primary credit rate) and is a proxy for inflation policy regime shifts, which appear to have a significant impact instead. Overall, the MSSA model confirms that Gibson's paradox was still present in the Netherlands after the II World War, in fact until 2008. The substantial fall in bond yields that occurred from 1978 was in fact accompanied by a fall in prices (until 1999). The loss of monetary policy independence in January 1999 could be a plausible explanation for the disappearance of Gibson's paradox after 2008.

Monte Carlo significance tests did not detect any significant deterministic and oscillatory patterns in the transformed LR series. Dutch bond yields cannot be distinguished from a red noise $\operatorname{AR}(1)$ process since the eigenvalues of LR lie within the red noise process bound. Since no significant oscillatory pair (extracted spectral components) outside the red noise bound has been found, the null hypothesis of transformed LR series following a red noise process, i.e. an $\mathrm{AR}(1)$ one, cannot be rejected. Thus, movements in LR cannot be explained by trend, periodic or oscillatory components in the series. This implies that the MSSA analysis of the bivariate relationship between LR and LCPI is necessary to describe the LR dynamics.

Statistically significant oscillatory patterns in LR and LCPI fluctuate around the frequency $0.18-0.20$ indicating a possible five-year cycle. Since they do not repeat themselves over time, they cannot be defined as cycles in Gibson's paradox. The calculated eigenvalue pairs are not statistically significant for either short or high frequencies. This implies that changes in LR and LCPI during the 1-4 year period and $>6$ periods have no significant impact on the relationship between LR and LCPI. Variations in Gibson's paradox can be explained by fluctuations in interest rates and prices over the 5-5.5 year's period. Changes in the cost of living have no direct and immediate effect on the long-term interest rates. This is in accordance with the results of Mises and Greaves (2011). The eigenvalues functions for LR and LCPI (not displayed here) in fact slowly increase from 0 , reaching a maximum after 5.5 years and slowly decaying thereafter.

The MSSA analysis once again supports the existence of Gibson's paradox in the Netherlands, identifying 5-5.5 year oscillations in LR and LCPI. The results are presented in Table 3, which displays the identified principal (spectral) components and the associated total variance explained by the significant eigenvalues pairs.
Multivariate SSA: Variable-Based Results $(\mathbf{m}=\mathbf{5 0})$

\begin{tabular}{lcccc}
\hline \multicolumn{1}{c}{ Series } & Frequency & Power & $\begin{array}{c}\text { \% of } \\
\text { variance } \\
\text { Explained }\end{array}$ & $\begin{array}{c}\text { \% of } \\
\text { cumulative } \\
\text { variance } \\
\text { Explained }\end{array}$ \\
\hline LR* & 0.003 & 61.3 & 9.18 & 9.18 \\
LCPI & 0.018 & 16.5 & 2.47 & 11.65 \\
DEBT & 0.035 & 13.6 & 2.04 & 13.69 \\
VOL & 0.082 & 13.5 & 2.02 & 15.71 \\
EXPSTIR* & 0.111 & 13.4 & 2.01 & 17.72 \\
GOLDSIL & 0.03 & 13.0 & 1.95 & 19.67 \\
TURNOVER & 0.081 & 12.9 & 1.94 & 21.61 \\
RORK2* & 0.111 & 12.0 & 1.8 & 22.69 \\
UN & 0.019 & 11.6 & 1.75 & 24.44 \\
M1* & 0.174 & 11.2 & 1.68 & 26.12 \\
EXPP* & 0.174 & 10.7 & 1.61 & 27.73 \\
DR* & 0.202 & 10.5 & 1.58 & 29.31 \\
NIR6* & 0.202 & 10.5 & 1.58 & 30.89 \\
EXP3* & 0.136 & 10.3 & 1.56 & 32.45 \\
PPG* & 0.136 & 10.0 & 1.50 & 33.95 \\
\hline & & & & \\
\hline
\end{tabular}

Source: Author's calculations

Notes. * patterns significantly $(p<.05)$ different from Monte Carlo (1000) simulated red noise

Table 2 confirms the multivariate and complex nature of Gibson's paradox. Of the 15 spectral components, 4 eigenvalue pairs passed the Monte Carlo test. The price level (LCPI) and unemployment (UN) eigenvalue pair is only weakly significant with eigenvalues towards the upper bounds of the confidence interval. Autoregressive (long memory) movements in bond yields explain $9.18 \%$ (partial variance) of the total variance. The pairs EXPSTIR and RORK2 account for $3.81 \%$ of the total variance of the series. Short-term interest rates and returns on capital are clearly distinguishable from the AR(1) red noise process. The DEBT and GOLDSIL eigenvalue pair instead fail to pass a red noise Monte Carlo test (i.e., they are not significantly different from the red noise), and the same holds for the VOL and TURNOVER eigenvalue pair. The other pairs (M1 and EXPP; DR and NIR6; EXP3 and PPG) capture $3.29 \%, 3.16 \%$ and $3.06 \%$ respectively of the total variance and in all cases are significantly different from the simulated red noise at the $95 \%$ confidence level.

LCPI and UN are not statistically suggesting that some important oscillatory components might have been left out; therefore, an MSSA model with a different windows size $(\mathrm{m}=100)$ is also estimated following Golyandina et al. (2010) and the general rule $m=N / 2$. As expected, choosing a bigger window size results in more significant oscillatory patterns being identified.

Both the LR and LCPI oscillations now appear to be significantly different from the simulated red noise process. VOL and EXPSTIR are now weakly significant, as are the other previously identified significant eigenvalues pairs (implying rejections of the red noise null hypothesis), as can be seen from Table 4. 
Estimating MSSA with different window sizes leads to the same conclusion. Overall, there is clear evidence that Gibson's paradox in the Netherlands is a multivariate phenomenon that can be explained by a large number of variables. Nine (9) PCA components (statistically significant eigenvalues) were identified with an MSSA $(\mathrm{m}=100)$ model explaining $34.58 \%$ of the total variance.

Table 4

Multivariate SSA: Variable-Based Results $(\mathbf{m}=100)$

\begin{tabular}{lcccc}
\hline \multicolumn{1}{c}{ Series } & Frequency & Power & $\begin{array}{c}\text { \% of } \\
\text { variance } \\
\text { explained }\end{array}$ & $\begin{array}{c}\text { \% of } \\
\text { cumulative } \\
\text { variance } \\
\text { explained }\end{array}$ \\
\hline LR $^{*}$ & 0.000 & 74.5 & 6.03 & 6.03 \\
LCPI* & 0.003 & 52.9 & 4.28 & 10.3 \\
DEBT & 0.02 & 27.6 & 2.24 & 12.5 \\
VOL & 0.081 & 27.2 & 2.21 & 14.7 \\
EXPSTIR & 0.082 & 27.1 & 2.20 & 16.9 \\
GOLDSIL & 0.031 & 25.0 & 2.02 & 18.9 \\
TURNOVER & 0.032 & 24.6 & 1.99 & 20.9 \\
RORK2 $*$ & 0.111 & 24.1 & 1.95 & 22.9 \\
UN & 0.021 & 23.8 & 1.93 & 24.8 \\
M1* & 0.125 & 20.7 & 1.68 & 26.5 \\
EXPP* & 0.176 & 20.3 & 1.64 & 28.1 \\
DR* & 0.176 & 20.1 & 1.63 & 29.8 \\
NIR6* & 0.202 & 19.7 & 1.60 & 31.4 \\
EXP3* & 0.109 & 19.6 & 1.59 & 32.9 \\
PPG* & 0.203 & 19.6 & 1.59 & 34.5 \\
\hline
\end{tabular}

Source: Author's calculations

Notes. * patterns significantly $(p<.05)$ different from Monte Carlo (1000) simulated red noise
The patterns emerging from the table above were reconstructed in the time domain using MSSA for tracing a limit cycle. The identified cycle has a period of 5-5.5 years and captures $34.58 \%$ of the total variance. The significant oscillatory components approximate well the dynamical behaviour of LR.

The reconstruction based on the MSSA components 1(LR), 2(LCPI), 3(RORK2), 4(M1), 5(EXPP), 6(DR), 7(NIR6), 8(EXP3), 9(PPG) explains well the fluctuations in long-term bond yields. Changes in prices and lagged interest rates account for most of the variance of the LR series. The return on capital and money supply eigenvalues do not differ significantly from other dominant eigenvalues. In fact, they capture approximately a similar percentage of the total variance. The expected profit rate, expected inflation and the natural interest rate oscillatory movements account for some of the fluctuations in bond yields. Changes in purchasing power and the DNB official discount rate also play a role. Comparing the reconstructed series with the original pre-processed LR series several points emerge. Structural shocks, breaks in the series such as the creation of De Netherlands Bank (1814), followed by the 1831 Belgium crisis, the industrial development phase starting in 1848 , the prosperity phase starting in 1920 the end of the golden age in 1974, the first and the second crisis under the EMS regime (1981 and 1990 respectively), explain some of the fluctuations in bond yields. On the whole, the identified principal components track well their behaviour over the period 1800-2012.

\section{Multivariate Spectral Granger Causality Analysis}

Table 5 shows the results of the multivariate spectral Granger causality analysis. Both unidirectional and bidirectional feedback between the series is examined. Evidence of bidirectional feedback is found in four cases, namely between LR and LCPI, LR and M1, LR and DR, LR and EXP3.

Table 5

Multivariate Spectral Granger Causality Analysis

\begin{tabular}{|c|c|c|}
\hline Causality relation & $F_{X \mid Y}^{(h, d)}$ & $F_{Y \mid X}^{(h, d)}$ \\
\hline MSSA forecast MSE of LR (LCPI as second series) & $(L C P I \rightarrow L R) 0.99 *$ & $(L R \rightarrow L C P I) 0.81^{*}$ \\
\hline MSSA forecast MSE of LR (RORK2 as second series) & $(\mathrm{RORK} 2 \rightarrow \mathrm{LR}) 0.99 *$ & $(\mathrm{LR} \rightarrow \mathrm{RORK} 2) 1.15$ \\
\hline MSSA forecast MSE of LR (M1 as second series) & $(M 1 \rightarrow L R) 0.99 *$ & $(L R \rightarrow M 1) 0.29 *$ \\
\hline MSSA forecast MSE of LR (EXPP as second series) & $(\mathrm{EXPP} \rightarrow \mathrm{LR}) 1.00$ & $(\mathrm{LR} \rightarrow \mathrm{EXPP}) 0.80^{*}$ \\
\hline MSSA forecast MSE of $L R$ (DR as second series) & $(D R \rightarrow L R) 0.95 *$ & $(L R \rightarrow D R) 0.98^{*}$ \\
\hline MSSA forecast MSE of LR (NIR6 as second series) & $(\mathrm{NIR} 6 \rightarrow \mathrm{LR}) 1.01$ & $(\mathrm{LR} \rightarrow \mathrm{NIR} 6)$ 0.18* \\
\hline MSSA forecast MSE of LR (EXP3 as second series) & $(E X P 3 \rightarrow L R) 0.98 *$ & $(L R \rightarrow E X P 3) 0.89 *$ \\
\hline MSSA forecast MSE of LR (PPG as second series) & $(\mathrm{PPG} \rightarrow \mathrm{LR}) 0.98^{*}$ & $(\mathrm{LR} \rightarrow \mathrm{PPG}) 1.70$ \\
\hline
\end{tabular}

Source: Author's calculations

Notes. $(X \rightarrow Y) X$ Granger cause $Y$ and $(Y \rightarrow X) Y$ Granger cause X, results statistically significant at $5 \%$ level.

MSE-mean squared forecast error, $F_{X \mid Y}^{(h, d)}$ Granger causality multivariate spectral criterion, * Granger cause

For example, using extra information from the LCPI series (MSSA) improves the accuracy of the one-step ahead forecast compared to the univariate forecast (SSA). The same holds for the return on capital, money supply, the official discount DNB rate, expected inflation and purchasing power. As a check of the spectral Granger causality test results, the Mariano and Diebold (1995) statistical test is then applied (see Table 6). 
Diebold-Mariano Test Statistics for $h$ Step Ahead Forecast $(h=40)$

\begin{tabular}{lcc}
\hline Forecasting Method & Test Statistics \\
\hline SSA of LR & 1.424 & P-value \\
SSA of LR against MSSA of LR (LCPI as second series) & $1.423^{*}$ & $1.416^{*}$ \\
SSA of LR against MSSA of LR (RORK2 as second series) & 1.442 \\
SSA of LR against MSSA of LR (M1 as second series) & 1.438 \\
SSA of LR against MSSA of LR (EXPP as second series) & $1.404^{*}$ \\
SSA of LR against MSSA of LR (DR as second series) & 1.457 \\
SSA of LR against MSSA of LR (NIR6 as second series) & $1.403^{*}$ \\
SSA of LR against MSSA of LR (EXP3 as second series) & 0.47 \\
SSA of LR against MSSA of LR (PPG as second series) & 0.43 \\
\hline
\end{tabular}

Source: Author's calculations

Notes. Null hypothesis - forecast accuracy of prediction methods is equal

MSSA forecasting method provides better forecasts, * gives higher predictive accuracy

The test results show that the MSSA-based forecasts outperform the SSA-based ones (lower MSE), supporting the conclusions from the multivariate spectral Granger causality analysis. Table 5 presents the results that are statistically significant at the $5 \%$ level. For long term interest rates on consols, our model gives better prediction for the LR dynamics 1 steps ahead (1 year), and suggests that long-term interest rate dynamics are highly influenced by other macroeconomic variables.

\section{Conclusions}

This paper investigates Gibson's paradox in the Netherlands over the period 1800-2012 using nonlinear spectral methods (namely, SSA and MSSA) and a large set of potential explanatory variables, unlike previous studies considering at most two. Our study offers a non-linear approach to the study of the Gibson's law contributing to the literature on the in the field by identifying main determinants behind the empirical relationship between interest rates and prices observed by Gibson (1923). The fifteen variables included in the selected model explain 35 $\%$ of the total variance in bond yields over the period examined, providing strong evidence of the existence of the paradox in the Netherlands. The results are consistent with previous studies on the Gibson's paradox by Fields (1984), Fase (1972) and opposed to the results in the study of Ram
(1987). An even higher percentage of the variance could have been explained if variables such as the DNB gold reserves could have been included, but unfortunately the relevant data are only available from 1875 . Although policy regime changes (such as the adoption of the classical gold standard or the loss of central bank independence when the Netherlands joined EMU) appear to affect the relationship, as also argued by Cogley et al. (2011) in the case of the US), they cannot account for it since it appears to be present under all the various regimes. The results of this study highlight the existence of a 5-5.5 year oscillatory pattern in long-term bond yields in the Netherlands. Furthermore, our results suggest that Gibson's paradox is a very complex phenomenon, that cannot easily be explained by exogenous shocks (Keynes' effect, Fishers' effect, Summers' effect, Wicksell's effect) or standard liquidity preference, loanable funds and rational expectations models. Nonlinearities are clearly an important feature of this relationship which should be modelled explicitly to understand its dynamic properties. The current research was limited by the available data and methodology used. Further work should examine other potential variables and available databases that might help explain the Gibson's paradox in more details and on more sound theoretical ground. In particular, derive a more robust time series model (fractional integration model) to explore the long memory properties of the paradox.

\section{References}

Allen, M. R., \& Smith, L. A. (1996). Monte Carlo SSA: Detecting irregular oscillations in the presence of colored noise. Journal of Climate, 9(1), 3373-3404. https://doi.org/10.1175/1520-0442(1996)009<3373:MCSDIO>2.0.CO;2

Barro, R. J., \& Ursua, J. F. (2008). Macroeconomic crises since 1870. NBER Working Papers, (13940). https://doi.org/10.3386/w13940

Barsky, R. B. (1987). The Fisher hypothesis and the forecastability and persistence of inflation. Journal of Monetary Economics, 19(1), 3-24. https://doi.org/10.1016/0304-3932(87)90026-2

Barsky, R. B., \& Summers, L. H. (1988). Gibson's paradox and the gold standard. The Journal of Political Economy, 528550. https://doi.org/10.1086/261550

Belke, A. (2016). Global liquidity and strategies of exit from unconventional monetary policies. Economic ResearchEkonomska Istrazivanja, 29(1), 286-313, https://doi.org/10.1080/1331677X.2016.1168039

Bos, F. (2008). The Dutch fiscal framework: history, current practice and the role of the central planning bureau. $O E C D$ Journal on budgeting, 8(1), 7-48. 
Broock, W. A., Scheinkman, J. A., Dechert, W. D., \& LeBaron, B. (1996). A test for independence based on the correlation dimension. Econometric Reviews, 15(3), 197-235. https://doi.org/10.1080/07474939608800353

Caselli, F., \& Feyrer, J. (2007). The marginal product of capital, the quarterly journal of economics, 122(2), 535-568. https://doi.org/10.1162/qjec.122.2.535

CBS - Historical series - Publications, (http://www.cbs.nl/en-GB/menu/themas/dossiers/historische-reeksen/cijfers/extra/ historische-reeksen.htm). Web page accessed 15.04.2013. Statistics Netherlands.

Casares, M., \& Vazquez, J. (2018). The swings of us inflation and the Gibson paradox. Economic Inquiry, 56(2), 799-820. https://doi.org/10.1111/ecin.12523

Cheng, H., Kesselring, R. G., \& Brown, C. R. (2013). The Gibson paradox: evidence from China. China Economic Review, 27, 82-93. https://doi.org/10.1016/j.chieco.2013.08.001

Clayton, G., Gilbert, J. C., \& Sedgwick, R. (1971). Monetary theory and monetary policy, in the 1970s: proceedings of the 1970 Sheffield Money Seminar. Oxford University Press.

Cogley, T., Sargent, T. J., \& Surico, P. (2011). The return of the Gibson paradox, in Federal Reserve Bank of Atlanta Working Papers.

Dajcman, S. (2015). Nonlinear spillovers between Euro area sovereign bond markets. Economics and Sociology, 8(1), 2840. https://doi.org/10.14254/2071-789X.2015/8-1/3

Elsner, J. B., \& Tsonis, A. A. (1996). Singular spectrum analysis: a new tool in time series analysis, Springer. https://doi.org/10.1007/978-1-4757-2514-8

Engle, R. F. (1976). Interpreting spectral analyses in terms of time-domain models. Annals of Economic and Social Measurement, 5(1), 89-109.

Faria, J. R., \& McAdam, P. (2012). A new perspective on the gold standard: inflation as a population phenomenon. Journal of International Money and Finance, 31(6), 1358-1370. https://doi.org/10.1016/j.jimonfin.2012.02.005

Fase, M. (1972). Bond yields and expected inflation: a quantitative analysis of the Dutch experience, De Nederlandsche Bank.

Fields, T. W. (1984). A re-examination of the Gibson paradox. Garland Pub.

Fisher, I. (1930). The theory of interest (Vol. 43). New York: The Macmillan Company.

Friedman, M., \& Schwartz, A. J. (1976). From Gibson to Fisher (pp. 130-133). Presented at the Explorations in Economic Research, Volume 3, number 2 (Conference on International Trade, Finance, and Development of Pacific Basin Countries, December 6/7, 1974, NBER.

Ghil, M., \& Yiou, P. (1996). Spectral methods: what they can and cannot do for climatic time series. decadal climate variability: dynamics and predictability, in D. Anderson and J. Willebrand (Eds.), Elsevier, pp. $446-482$. https://doi.org/10.1007/978-3-662-03291-6_11

M. Ghil, M. R. Allen, M. D. Dettinger, K. Ide, D. Kondrashov, M. E. Mann, A. W. Robertson, A. Saunders, Y. Tian, F. Varadi, P. Yiou. (2002). Advanced spectral methods for climatic time series. Reviews of Geophysics, 40(1), 1003. https://doi.org/10.1029/2000RG000092

Gibson, A. H. (1923). The future course of high class investment values. Banker's Magazine (London), 115, 15-34.

Golyandina, N., \& Zhigljavsky, A. (2013). Singular spectrum analysis for time series. Springer. https://doi.org/10.1007/9783-642-34913-3

Golyandina, N., Nekrutkin, V., \& Zhigljavsky, A. A. (2010). Analysis of time series structure: SSA and Related Techniques, CRC Press.

Gonzalez, E., Melo, L. F., Rojas, L. E., \& Rojas, B. (2010). Estimations of the natural rate of interest in Colombia (No. 626). banrep.gov.co (Banco De La Republica Colombia.). Bogota.

Granger, C. W. J., \& Hatanaka, M. (1964). Spectral analysis of economic time series, Princeton Studies in Mathematical Economics, Princeton University Press.

Groote, P., Albers, R., \& De Jong, H. (1996). A standardised time series of the stock of fixed capital in the Netherlands, 1900-1995. Groningen Growth and Development Centre, Faculty of Economics, University of Groningen.

Groth, A. A., \& Ghil, M. M. (2011). Multivariate singular spectrum analysis and the road to phase synchronization. Physical Review E, 84, 036206. https://doi.org/10.1103/PhysRevE.84.036206

Hamilton, J. D. (1994). Time series analysis, Cambridge University Press.

Hart, M., Jonker, J., \& van Zanden, J. L. (2010). A financial history of the Netherlands. Cambridge University Press.

Harvey, A. C. (1990). Forecasting, structural time series models and the Kalman filter. Cambridge university press. https://doi.org/10.1017/CBO9781107049994

Hassani, H., Zhigljavsky, A., Patterson, K., \& Soofi, A. (2011). A comprehensive cxausality test based on the singular spectrum analysis, in Phyllis McKay Illari, Federica Russo, Dr., Jon W., Causality in the sciences, Oxford University Press. 
Hassani, H., Mahmoudvand, R., \& Zokaei, M. (2011). Separability and window length in singular spectrum analysis. Comptes Rendus Mathematique, 349(17), 987-990. https://doi.org/10.1016/j.crma.2011.07.012

Hassani, H., \& Mahmoudvand, R. (2013). Multivariate singular spectrum analysis: a general view and new vector forecasting approach. International Journal of Energy and Statistics, 1(01), 55-83. https://doi.org/10.1142/S2335680413500051

Hassani, H., Heravi, S. and Zhigljavsky, A. (2012). Forecasting UK industrial production with multivariate singular spectrum analysis. Journal of Forecasting, 32(5), 395-408. https://doi.org/10.1002/for.2244

Homepage Statistics - De Nederlandsche Bank, (http://www.dnb.nl/en/home/), web page accessed 15.02.2013.

Hassani, H., Mahmoudvand, R., Zokaei, M., \& Ghodsi, M. (2012). On the separability between signal and noise in singular spectrum analysis. Fluctuation and Noise Letters, 11(02), 1250014. https://doi.org/10.1142/S0219477512500149

Homer, S., \& Sylla, R. (2011). A history of interest rates, Wiley \& Sons Press.

International Institute of Social History (http://socialhistory.org, web page accessed 16.03.2013), International Institute of Social History. Royal Netherlands Academy of Arts and Sciences.

Jacobs, J., \& Smits, J.P. (2001). Business cycles in the Netherlands, 1815-1913. University of Groningen.

Keynes, J. M. (1930). A treatise on money, reprinted in Martino Publishing, 2011.

Kocenda, E., (2001). An alternative to the BDS test: integration across the correlation integral. Econometric Reviews, 20(3), 337-351. https://doi.org/10.1081/ETC-100104938

Mariano, R. S., \& Diebold, F. X. (1995). Comparing predictive accuracy. Journal of Business \& Economic Statistics, 13, 253-265.

Mills, T. C. (2008). Exploring historical economic relationships: two and a half centuries of British interest rates and inflation. Cliometrica, 2(3), 213-228. https://doi.org/10.1007/s11698-007-0023-3

Mirza, N., Rahat, B., \& Reddy, K. (2016). Financial leverage and stock returns: evidence from an emerging economy. Economic Research - Ekonomska Istrazivanja, 29(1), 85-100. https://doi.org/10.1080/1331677X.2016.1160792

Mises, von, L., \& Greaves, B. B. editor (2011). On the manipulation of money and credit: three treatises on trade-cycle theory, Liberty Fund Incorporated.

Netherland, S. (2010). 111 Jaar statistiek in tijdreeksen, 1899-2010, cbs.nl. Roterdam, Central Bureau of Statistics, the Netherlands.

Netherland, S. (2012). National accounts of the Netherlands 2011, cbs.nl. The Hague/Heerlen: Statistics Netherlands.

Officer, L. H., \& Williamson, S. H. Measuring Worth (2013). Measuringworth.com. Measuring Worth, web page accessed 16.03.2013.

Priestley, M. B. (1981). Spectral analysis and time series, Elsevier Academic Press.

Ram, R. (1987). A broader multicountry perspective on the Gibson paradox and fisher's hypothesis, De Economist, 135(2), 219-230. https://doi.org/10.1007/BF01718263

Rizwan, R. A., Vveinhardt, J., Streimikiene, D., \& Fayyaz, M. (2017). Multivariate Granger causality between macro variables and KSE 100 index: evidence from Johansen cointegration and Toda \& Yamamoto causality. Economic Research - Ekonomska Istrazivanja, 30(1), 1497-1521. https://doi.org/10.1080/1331677X.2017.1340176

Shiller, R. J., \& Siegel, J. J. (1977). The Gibson paradox and historical movements in real interest rates, The Journal of Political Economy, 85(5), 891-907. https://doi.org/10.1086/260614

Smits, J. P., Horlings, E., \& Van Zanden, J. L. (2000). Dutch GNP and its components, 1800-1913. Groningen Growth and Development Centre.

van Bochove, C. A., \& Huitker, T. A. (1987). Main national accounting series, 1900-1986. cbs.nl. Central Bureau of Statistics, The Netherlands.

van den End, J. W. (2011). Statistical evidence on the mean reversion of interest rates. Netherlands Central Bank, Research Department. https://doi.org/10.2139/ssrn.1950596

Waldemar, G., \& Maciej, Z. (2016). The ability to assimilate technology as a source of competitive advantage of financial companies in Poland. Journal of Competitiveness, 8(4), 61-71. https://doi.org/10.7441/joc.2016.04.04

Warner, R. M. (1998). Spectral analysis of time-series data, Guilford Press.

Zanden, V. J., \& Lindblad, J. T. (1989). De buitenlandse handel van Nederland, 1872-1913. Economisch-en sociaalhistorisch jaarboek, 52, 231-269.

Zanden, V. J., \& Riel, A. V. (2000). Nederland 1780-1914. Staat, instituties en economische ontwikkeling, Balans.

The article has been reviewed.

Received in March, 2018; accepted in September, 2018. 